\title{
A significant improvement in material of foam
}

\author{
Ankica Đukić ${ }^{\mathrm{a}, *}$, Vesna Alar $^{\mathrm{b}}$, Mihajlo Firak ${ }^{\mathrm{a}}$, Suzana Jakovljević ${ }^{\mathrm{c}}$

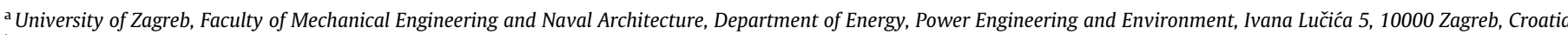 \\ ${ }^{\mathrm{b}}$ University of Zagreb, Faculty of Mechanical Engineering and Naval Architecture, Department of Welded Structures, Ivana Lučića 5, 10000 Zagreb, Croatia \\ ${ }^{\mathrm{c}}$ University of Zagreb, Faculty of Mechanical Engineering and Naval Architecture, Department of Materials, Ivana Lučića 5, 10000 Zagreb, Croatia
}

\section{A R T I C L E I N F O}

\section{Article history:}

Received 30 January 2013

Received in revised form 3 April 2013

Accepted 5 April 2013

Available online 12 April 2013

\section{Keywords:}

Hydrogen production

Alkaline electrolyser

Electrodes

Nickel foam

Electrochemical measurements

\begin{abstract}
A B S T R A C T
In investigation of different materials for electrodes used in electrolysers for hydrogen production, nickel foam shows wide interests in hydrogen scientific community. This paper brings novel results of performed experiments on pure nickel foam and nickel foam silver coated. The electrochemical behavior of chosen material in high concentrated alkaline media was studied using potentiostatic and potentiodynamic DC and AC electrochemical methods: linear polarization, electrochemical impedance spectroscopy. It was shown that using silver coatings enable higher hydrogen generation. There is defined linear region of the hydrogen production with evidence that an increasing of the electrodes overvoltage decreases the resistance to the charge transfer.
\end{abstract}

(c) 2013 Elsevier B.V. All rights reserved.

\section{Introduction}

Investigations focused on hydrogen as the fuel are mostly oriented on possibilities of the system efficiency improvement [14 ]. As long as there does not exist hydrogen as a free element on the earth, it has to be produced. Energy needed for the process of hydrogen production can be used from the renewable energy sources (RESs), i.e. direct conversion of solar energy into electrical energy using photovoltaic modules [3,5-10]. The oldest process for hydrogen production is the process of water electrolysis where the most important component of the system is the type of a chosen material for the electrodes design. Nickel $(\mathrm{Ni})$ is a frequently used material in hydrogen generation process because of its good properties both as the catalyst and the electrode [11-15]. It is founding in forms of a bulk, the foam, a raney, a mesh and different alloys. The investigations for comparison of the bulk and pure foam have been already done where obtained results gave improved process using pure foam [13]. As the progressive continuation of that author's work, in this investigation experiments, both on the pure $\mathrm{Ni}$ foam and $\mathrm{Ni}$ foam silver $(\mathrm{Ag})$ coated, were performed. It was chosen Ag because of its highest electrical conductivity in the comparison to the other elements in a high concentrated alkaline media. Experimental setup used for the experiments of hydrogen evolution reaction (HER) was designed as the three electrodes system with electrolyte of $25 \% \mathrm{KOH}$ alkaline solution in all performed measurements. An improved catalytic activity of a three dimen-

\footnotetext{
* Corresponding author. Tel.: +385 16168218.

E-mail address: ankica.djukic@fsb.hr (A. Đukić).
}

sional (3D) Ni foam is attributed to the increased active surface area. This work is realized to achieve the wanted goal of system efficiency increasing. In accordance with that wanted goal the measurements were carried out to define electrodes parameter related to the electrolysers operation. A behavior of the investigated material was studied using potentiostatic and potentiodynamic Direct current $(D C)$ and Alternating Current $(A C)$ electrochemical methods. The applied methods were Brunauer-Emmet-Teller (BET) method, Direct Current Electrochemical Methods (DCEMs), Electrochemical Impedance Spectroscopy (EIS), Scanning Electron Microscopy (SEM) and Energy Dispersive Spectroscopy (EDS) [16-20].

\section{Methodology}

The used methodology was chosen after preliminary definition of the needed parameters to investigate the effect of the coated foam. According to the wanted goals, DC and AC methods were defined. An active surface area of the foam needed to be defined using combination of measurement and calculation. A BET theory was developed in 1938 named by the author's last names initials: Stephen Brunauer, Paul Hugh Emmet and Edward Teller. It is the first method for specific surface measurements of finely divided and porous solids. Its application is based on adsorption of gas on the surface [21]. An analysis gas for described measurement was nitrogen $\left(\mathrm{N}_{2}\right)$. These measurements were carried out using device of Micromeritis, Asap 2000. The surface morphology and chemical composition of the foam were determined using a VEGA TESCAN TS 5136 MM Scanning Electron Microscope equipped with Oxford Instruments INCA energy dispersive spectroscopy. Electrochemical measurements were carried out in accordance with the requirements of ASTM standard of G 102-89 [22]. The preferred characterizations of the foam both pure and Ag coated were performed out using a device of EG\&G PAR 273A Potentiostat/Galvanostat. A standard electrochemical reactor was consisted of the graphite counter electrode, reference saturated calomel electrode $(+0.2415 \mathrm{mV})$ and working electrode of 
Table 1

Silver deposition solution.

\begin{tabular}{lcc}
\hline Component & Concentration (M) & Total time (min) \\
\hline $\mathrm{AgNO}_{3}$ & 0.1 & \\
Ammonia & 1.83 & 10 \\
Acetic acid & 0.73 & \\
Hydrazine-hydrate & 0.1 & \\
Additives & $<0.01$ &
\end{tabular}

Table 2

Summary report of BET method measurements.

\begin{tabular}{ll}
\hline Type & $\begin{array}{l}\text { Active surface area } \\
\left(\mathrm{m}^{2} \mathrm{~g}^{-1}\right)\end{array}$ \\
\hline BET & 1.9710 \\
Single point at P/Po 0.2002 & 0.8095 \\
BJH cumulative adsorption of pores between 17 and & 1.1083 \\
$\quad 300.000 \mathrm{~nm}$ diameter & \\
BJH cumulative desorption of pores between 1.7 and & 1.1488 \\
$\quad 300.000 \mathrm{~nm}$ & \\
\hline
\end{tabular}

active surface area of $1 \mathrm{~cm}^{2}$. The experiments were carried out using an electrolyte of $25 \% \mathrm{KOH}$ alkaline solution of $14 \mathrm{pH}$ at the ambient temperature of $22 \pm 2{ }^{\circ} \mathrm{C}$. The Tafel curves were recorded in the potential range of $\pm 250 \mathrm{mV}$ from the open circuit potential with a rate of potential change of the $0.5 \mathrm{~m} \mathrm{~V} \mathrm{~s}^{-1}$. Applying a method of Tafel extrapolation, values of wanted parameters were calculated according to the Stern-Geary equation written below [23]

$I_{\text {corr }}=(B \times \Delta i) / \Delta E$

$B=\left(b_{a} \times b_{c}\right) /\left[2.3 \times\left(b_{a}+b_{c}\right)\right]$

where $i_{\text {corr }}\left(\mathrm{mA} \mathrm{cm}^{-2}\right)$ is corrosion current density; $B(\mathrm{~V})$ is Stern-Geary constant; $\Delta i$ $\left(\mathrm{mA} \mathrm{cm}^{-2}\right)$ is corrosion current density change; $\Delta E(\mathrm{~V})$ is potential change; $b_{a}$ $\left(\mathrm{mV}\right.$ decade $\left.{ }^{-1}\right)$ is anodic slope of Tafel curve; $b_{c}\left(\mathrm{mV}\right.$ decade $\left.^{-1}\right)$ is cathodic slope of the Tafel curve.
The corrosion potential was recorded for $500 \mathrm{~s}$. During this time DC polarizations have been carried out at $10 \mathrm{mV} \mathrm{min}^{-1}$ scan rate $\left(\approx 0.17 \mathrm{mV} \mathrm{s}^{-1}\right)$. The measurements were performed using a device of EGG Instruments, Model 5210, Lock-in Amplifier.

\section{Experiments}

The previous investigations of the author have proven Ni foam as the material the most suitable for the process of water electrolysis in all levels of the experiments. Because of its porosity, the amount of produced hydrogen is higher in the comparison to the produced hydrogen using $\mathrm{Ni}$ solid electrodes at the same conditions. According to that, in this work were performed experiments on the foam with same characteristics but improved with Ag coating on its surface. These measurements were carried out as the continuation of the previous work to define parameters which directly take effects on the electrolyser operation [13]. The electrodes material used for the experiments was pure $\mathrm{Ni}$ foam (active surface area: $1510 \mathrm{~cm}^{2}$; density: $0.681 \mathrm{~g} \mathrm{~cm}^{-3}$ with porosity of $95-99 \%$ and nominal pore diameters of $600 \mu \mathrm{m}$, manufactured by Mitsubishi Materials Corporation, Japan) and $\mathrm{Ni}$ foam Ag coated (active surface area: $1531 \mathrm{~cm}^{2}$; density: $0.6905 \mathrm{~g} \mathrm{~cm}^{-3}$ ). The Ag layers were coated from $\mathrm{AgNO}_{3}$ based solution via electroless deposition method. Ammonia and acetic were used as a buffer to adjust the $\mathrm{pH}$ in the range from 10 to 10.6. In this solution metal ions of Ag were directly reduced into pure $\mathrm{Ni}$ foam by the involving of reducing agent of hydrazine-hydrate. A detailed bath composition is specified in Table 1 .

As long as it is used porous material, there is a need to define and calculate an active surface area. In this work, active surface area was measured and calculated via BET method. The foam was prepared as the samples of $5 \times 5 \times 2 \mathrm{~mm}$ with overall minimum weight of $1 \mathrm{~g}$. The surface morphology of the foam was characterized and defined via SEM as well as chemical structure observed via EDS. For these measurements of SEM, EDS, DCEM and EIS the foam was prepared as sample of $10 \times 10 \times 2 \mathrm{~mm}$ what matches to the $1 \mathrm{~cm}^{2}$ of geometrical surface area.

\section{Results and discussion}

All given results are in the accordance with wanted goals of the system efficiency increasing by using materials of improved performances. The important role in an increasing of electrolysers efficiency plays the active surface area which is proportional related to the hydrogen production. According to that, involving of the porous materials gives much larger active surface area in comparison with nonporous materials at the same geometrical surface area.
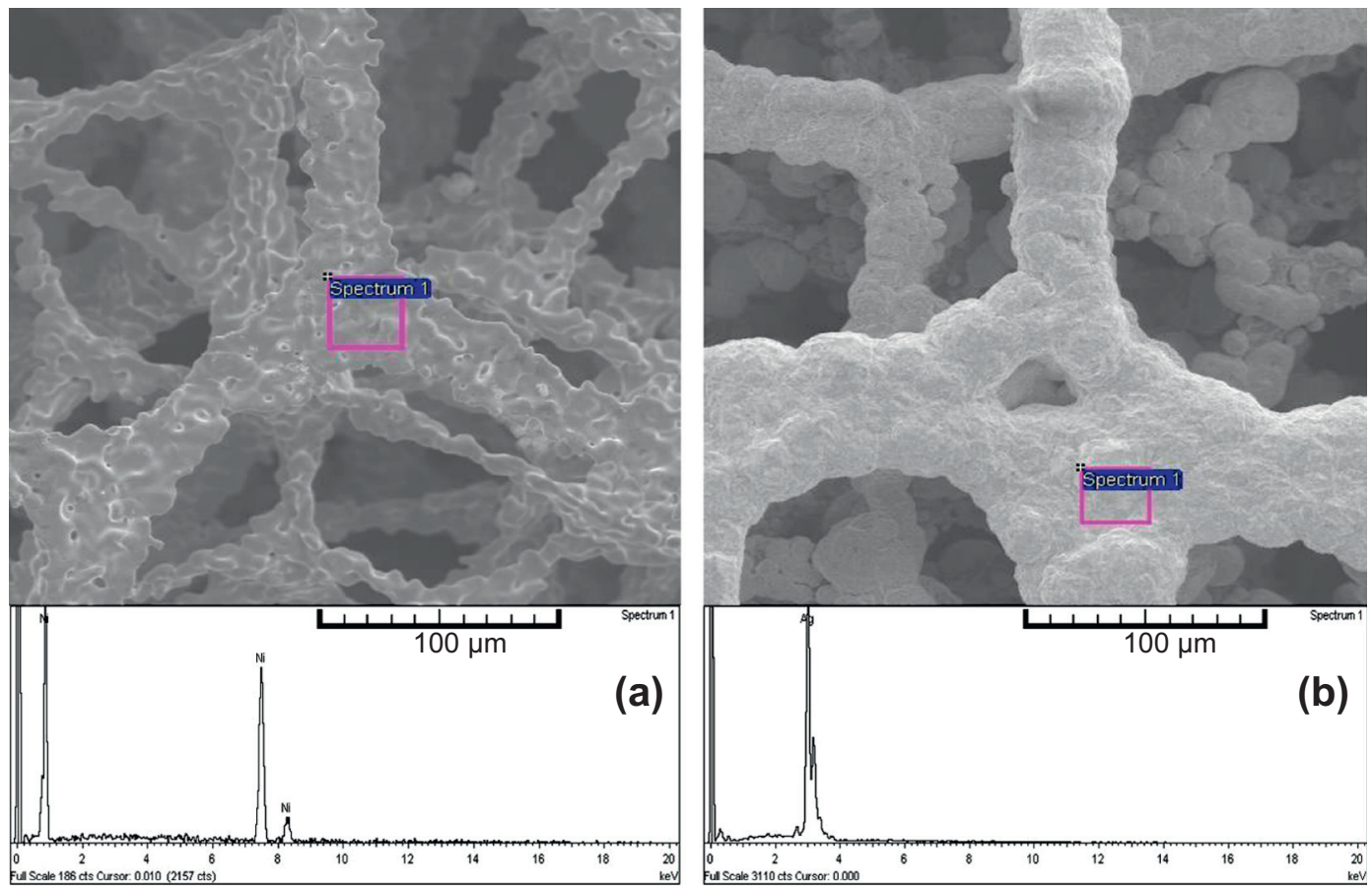

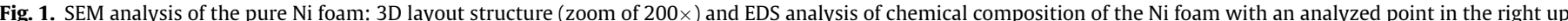

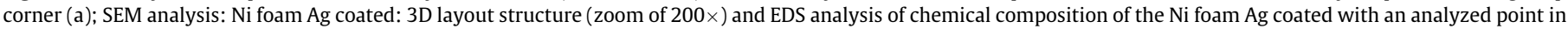
the right up corner (b). 


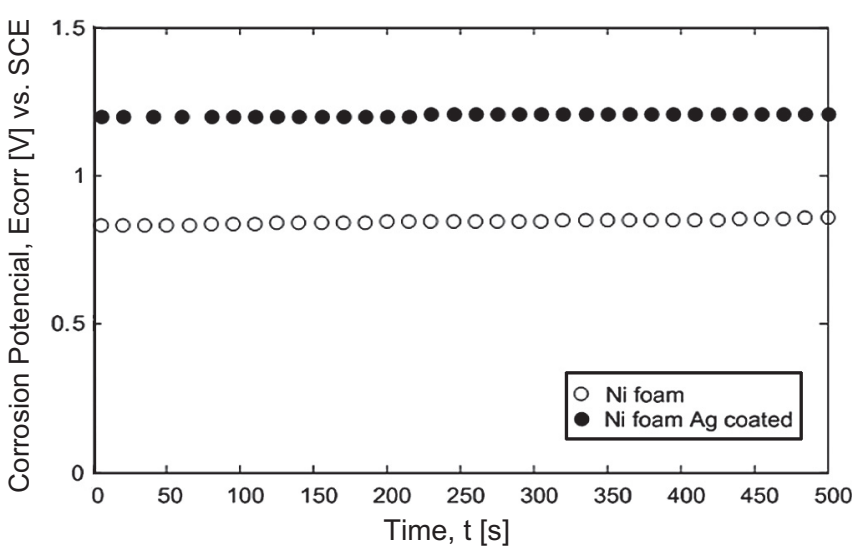

Fig. 2. Diagram of the corrosion potential $\left(E_{\text {corr }}\right)$ during the time of the $10 \mathrm{~min}$ on the pure $\mathrm{Ni}$ foam and $\mathrm{Ni}$ foam $\mathrm{Ag}$ coated in an electrolyte of $25 \% \mathrm{KOH}$ alkaline solution.

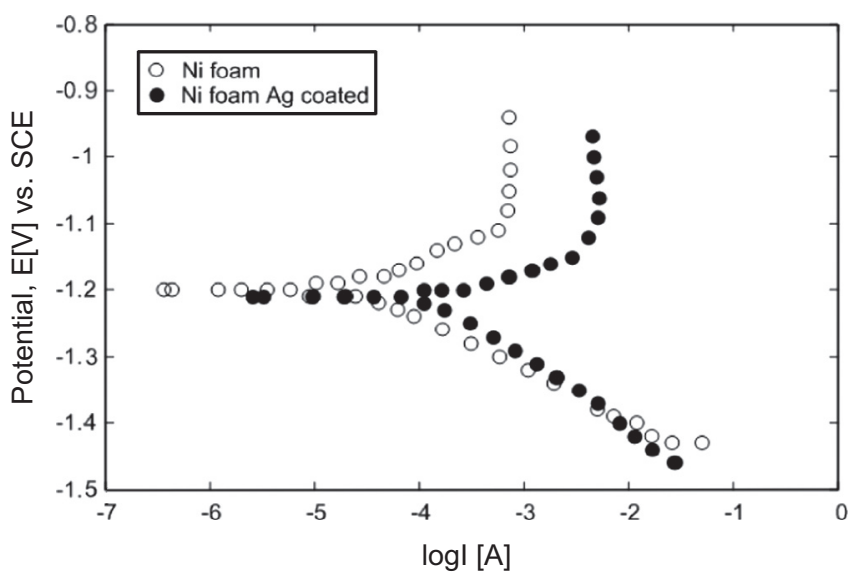

Fig. 3. Polarization curves, anodic and chatodic (Tafel) curves of pure Ni foam and $\mathrm{Ni}$ foam Ag coated in an electrolyte of $25 \% \mathrm{KOH}$ alkaline solution.

Table 3

Measured and calculated electrochemical parameters.

\begin{tabular}{clllll}
\hline & $\begin{array}{l}b_{a} \\
\left(\mathrm{~V} \mathrm{decade}^{-1}\right)\end{array}$ & $\begin{array}{l}b_{c} \\
\left(\mathrm{~V} \mathrm{decade}^{-1}\right)\end{array}$ & $\begin{array}{l}E_{\text {corr }}(\mathrm{V}) \\
\text { vs. SCE }\end{array}$ & $\begin{array}{l}i_{\text {corr }} \\
\left(\mathrm{Acm}^{-2}\right)\end{array}$ & $B(\mathrm{~V})$ \\
\hline $\begin{array}{c}\text { Pure Ni } \\
\text { foam }\end{array}$ & $5.81 \mathrm{e}-3$ & $76.01 \mathrm{e}-3$ & -1.16 & $24.42 \mathrm{e}-6$ & 0.015 \\
$\begin{array}{c}\text { Ni foam Ag } \\
\text { coated }\end{array}$ & $50.9 \mathrm{e}-3$ & $110.7 \mathrm{e}-3$ & -1.22 & $157.6 \mathrm{e}-6$ & 0.015 \\
\hline
\end{tabular}

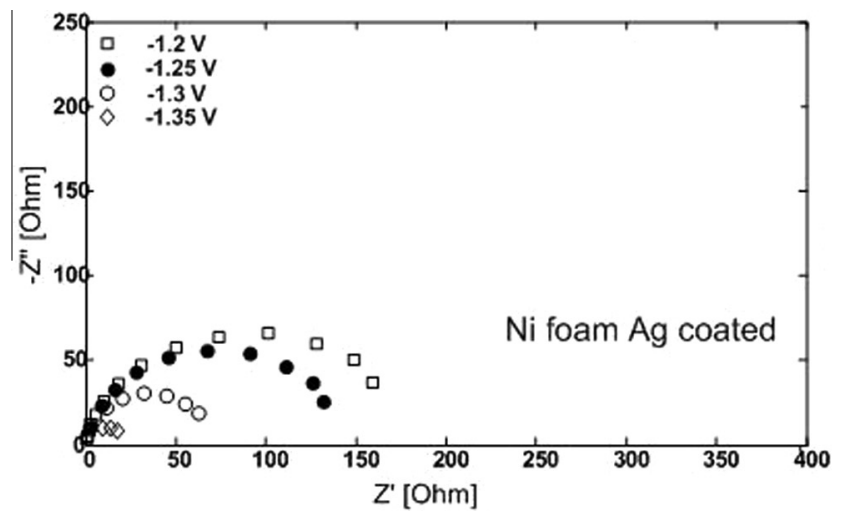

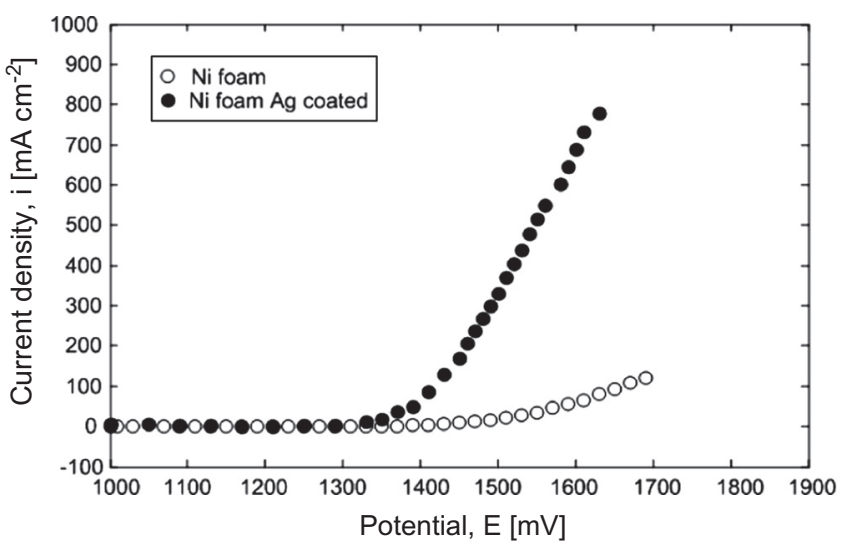

Fig. 4. Polarization curves of the pure $\mathrm{Ni}$ foam and $\mathrm{Ni}$ foam $\mathrm{Ag}$ coated in an electrolyte of $25 \% \mathrm{KOH}$ alkaline solution.

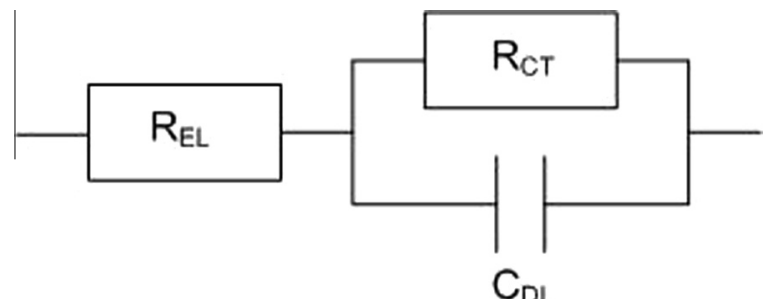

Fig. 6. An equivalent circuit of the pure Ni foam and Ni foam Ag coated electrodes for the EIS measurements where $R_{E L}(\Omega)$ is resistance of the electrolyte; $R_{C T}\left(\Omega \mathrm{cm}^{2}\right)$ is the charge transfer resistance and $C_{D L}(F)$ is the capacitance of the electrochemical double-layer.

Table 4

Values of parameters of the equivalent circuit pure $\mathrm{Ni}$ foam $\mathrm{Ni}$ foam $\mathrm{Ag}$ coated.

\begin{tabular}{lcccc}
\hline & Ni foam & \multicolumn{3}{c}{ Ni foam Ag coated } \\
\hline$E(\mathrm{~V})$ & -1.45 & -1.5 & -1.45 & -1.5 \\
$R_{E L}(\Omega)$ & 0.103 & 0.104 & 0.0831 & 0.0993 \\
$R_{C T}(\Omega)$ & 5.257 & 1.616 & 1.3669 & 0.5208 \\
$C_{D L}(\mathrm{~F})$ & 9.712 & 9.491 & 12.035 & 10.066 \\
\hline
\end{tabular}

This property of porosity transforms two-dimensional electrolyte flow (2D) to the three-dimensional (3D) electrolyte flow. The results of BET method are given in Table 2 .

A comparison of the geometrical surface area and an active surface area of the 3D electrodes gives approximately 1000 times lar-

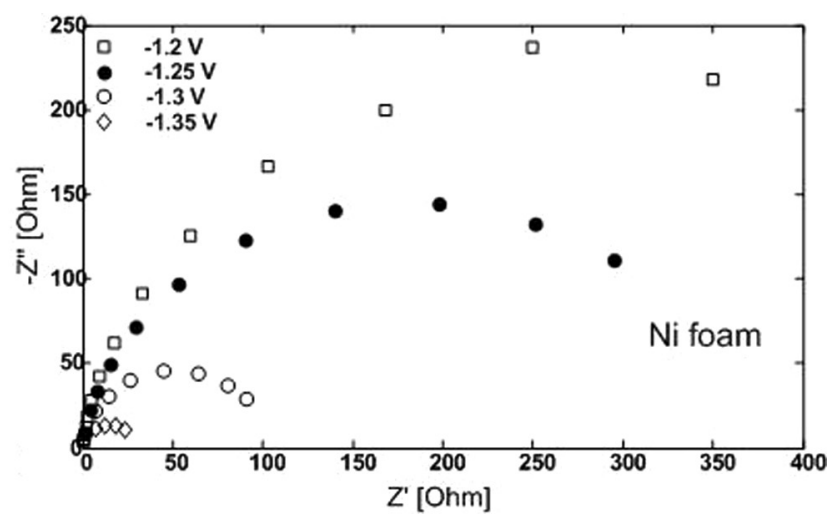

Fig. 5. Nyquist plots of the pure $\mathrm{Ni}$ foam and $\mathrm{Ni}$ foam $\mathrm{Ag}$ coated in an electrolyte of $25 \%$ of $\mathrm{KOH}$ alkaline solution in potential scale range from $-1.2 \mathrm{~V}$ to $-1.35 \mathrm{~V}$ with step size of $-0.5 \mathrm{~V}$. 

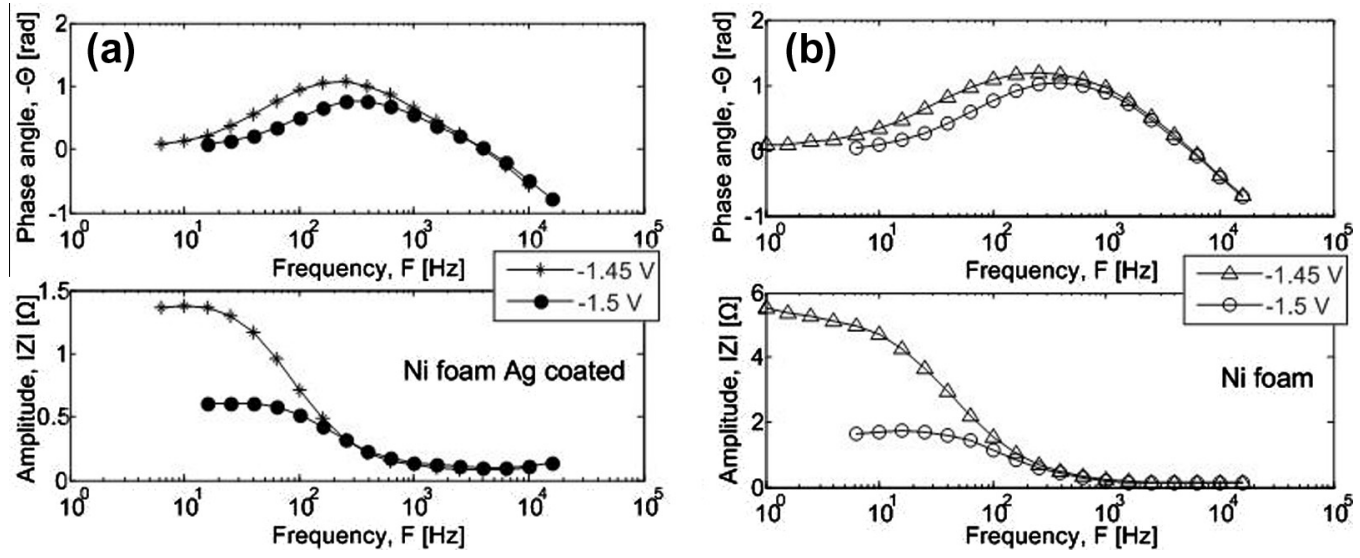

Fig. 7. Bode plots: Phase angle and amplitude of $\mathrm{Ni}$ foam $\mathrm{Ag}$ coated (a) and pure $\mathrm{Ni}$ foam (b) at the potentials of $-1.45 \mathrm{~V}$ and $-1.5 \mathrm{~V}$.

ger active surface area. This data depend on the electrodes weight what takes impact to the costs reduction. The surface morphology of the electrodes material via SEM analysis both of the pure $\mathrm{Ni}$ foam and Ni foam Ag coated is given in Fig. 1. From the SEM analysis it is seen 3D layout structure of the pure Ni foam and a view of intermediate connections between bones with diagrams of the chemical composition observed via EDS analysis.

Fig. 1 shows $\mathrm{Ni}$ foam of the $100 \%$ of the $\mathrm{Ni} \mathrm{(a)} \mathrm{and} \mathrm{Ni}$ foam $\mathrm{Ag}$ coated of $100 \%$ of the Ag intensity (b). For determination of the corrosion potential, Tafel slopes and polarization curves DCEM methods were used. In Fig. 2 it is given measurement of the corrosion potential. In recording time of $500 \mathrm{~s}$ the both analyzed samples of the foam shown stability needed for their application in a concentrated alkaline media.

The results of the measured corrosion potential gave Ag coating as more electropositive. During polarization within Tafel scanning it was seen a generation of protective passive film layers in regard to SCE at the potential of $-1.1 \mathrm{~V}$ for both testing samples of electrodes. The results are shown in Fig. 3.

Using Tafel extrapolation corrosion velocities were determined which because of their low values are negligible. The numeric results of the Tafel extrapolation are obtained in Table 3.

The obtained results are electrochemical parameters of anodic and cathodic Tafel slopes $\left(b_{a}\right.$ and $\left.b_{c}\right)$, corrosion potential $\left(E_{c o r r}\right)$, corrosion current density $\left(i_{\text {corr }}\right)$ and Stern-Geary constant $(B)$ which actually was calculated from the polarization curves. A given anodic Tafel slope with higher value insures higher hydrogen generation. Furthermore, wider anodic domain of $\mathrm{Ag}$ coating in Fig. 4 confirmed higher hydrogen generation using coated foam at the same voltage values.

A higher hydrogen evolution is enabled by the range of corrosion current density between $100 \mathrm{~mA} \mathrm{~cm}^{-2}$ and $800 \mathrm{~mA} \mathrm{~cm}^{-2}$. The results of Fig. 4 are obtained using DC polarizations. Obtained results for evaluating electrochemical impedance data are presented in the format of Nyquist plots. The responses for cell voltages of $1.2 \mathrm{~V}, 1.25 \mathrm{~V}, 1.3 \mathrm{~V}$ and $1.35 \mathrm{~V}$ are given in Fig. 5.

This plot illustrates the expected responses of the simple circuit but reached the goal of this investigation. From the plotted results there is seen that using $\mathrm{Ag}$ coating are obtained apparent lower resistances of the electrolyte. Hence, significantly reduced resistance to the charge transfer was achieved. According to the equivalent circuit of the single electrochemical cell shown in the Fig. 6, the numerical values of the parameters were calculated for the potentials of $-1.45 \mathrm{~V}$ and $-1.5 \mathrm{~V}$.

Calculations data are given in Table 4.

Graphical results are processed in the plotting format of Bode plot and shown in Fig. 7. It is graphically explained how impedance depends on the frequency.
The same as in the Nyquist plot, Bode plot also gave improved results obtained using Ag coating. At the highest value of frequency the impedance does not depend on it. It is defined by resistance of the electrolyte. For the same frequency values, pure $\mathrm{Ni}$ foam is defined with a greater resistance in comparison to the $\mathrm{Ni}$ foam $\mathrm{Ag}$ coated.

\section{Conclusions}

The investigations related to the electrodes material with application in an alkaline electrolyser for hydrogen production were carried out. Tested materials were pure nickel foam and nickel foam silver coated. A using of the porous material leads to the increasing of the electrolyser efficiency because of the increased active surface area of the porous material. Moreover, nickel as the good catalyst and electrode with an upgrading of the existing material by different chemical elements contributes to the improvement. The scientific contribution of this work is related to the active surface of 1500 times larger in comparison to the geometrical surface area. Recent progress in the electrodes design was involving of the silver coatings. From the aspect of polarization curves and impedance measurements, the obtained results shown wider range of the hydrogen generation using nickel foam silver coated. It provided an improved current collection compare to the pure nickel foam due to the reduction of the electrolyte resistance and charge transfer resistance. The increasing of the electrodes overvoltage decreases the resistance to the charge-transfer both at the nickel foam and nickel foam silver coated. According to the results of performed DC and AC methods, at the same voltages higher hydrogen generation using nickel foam silver coated was achieved. Mentioned improvements lead to the costs reduction in the electrolyser system related to the reduction of components size in the system in general. Future investigations will be based on durability time of the chosen material of electrodes in laboratory design electrolyser.

\section{References}

[1] L.D. Danny Harvey, Clim. Change 29 (1995) 53.

[2] M. Momirlan, T.N. Veziroglu, Renew. Sustain. Energy Rev. 6 (2002) 141

[3] Q. Ulleberg, Stand-Alone Power Systems for the Future: Optimal Design, Operation \& Control of Solar-Hydrogen Energy Systems, Dissertation, Norwegian University of Science and Technology, Trondheim, 1998.

[4] J.D. Holladay, J. Hu, D.L. King, J. Wang, Catal. Today 139 (2009) 244.

[5] C.A. Grimes, O.K. Varghese, S. Ranjan, Light, Water, Hydrogen, Springer, New York, 2008.

[6] E. Bilgen, Energy Convers Manage. 42 (2001) 1047.

[7] V. Quaschning, Understanding Renewable Energy Systems, Bath Press, London, 2005. 
[8] P. Biddyut, J. Andrews, Int. J. Hydrogen Energy 33 (2008) 490.

[9] R.E. Clarke, S. Giddey, F.T. Ciacchi, S.P.S. Badwal, B. Paul, J. Andrews, Int. J. Hydrogen Energy 34 (2009) 2531.

[10] H. Zhang, G. Lin, J. Chen, Int. J. Hydrogen Energy 35 (2010) 10851.

[11] M.E. Mert, G. Kardas, J. Alloys Comp. 509 (2011) 9190.

[12] F. Bidault, D.J.L. Brett, P.H. Middleton, N. Abson, N.P. Brandon, Int. J. Hydrogen Energy 35 (2010) 1783.

[13] A. Đukić, M. Firak, Int. J. Hydrogen Energy 36 (2011) 7799.

[14] X. Gao, J. Liu, S. Ye, D. Song, Y. Zhang, J. Alloys Comp. 253-254 (1997) 515

[15] Q. Han, X. Li, J. Chen, K. Liu, X. Dong, X. Wei, J. Alloys Comp. 400 (2005) 265.

[16] K. Ramya, N. Rajalakshmi, P. Sridhar, B. Sivasankar, J. Alloys Comp. 352 (2003) 315
[17] V. Afshari, C. Dehghanian, J. Electroanal. Chem. 3 (2010) 366.

[18] R. Abdel-Karim, J. Halim, S. El-Raghy, M. Nabil, A. Waheed, J. Alloy. Comp. 530 (2012) 85.

[19] S.K. Ghosh, G.K. Dey, R.O. Dusane, A.K. Grover, J. Alloy. Comp. 426 (2006) 235

20] C. Leinenbach, D. Eifler, Int. J. Mater. Res. 6 (2004) 535.

[21] S. Brunauer, P.H. Emmett, E. Teller, Contribution from the Bureau Chemistry and Soils and George Washington University 60 (1938) 309.

[22] ASTM G 102-89, Standard practice for calculation of corrosion rates and related information for electrochemical measurements ASTM standards, Philadelphia (1989).

[23] P.R. Roberge, Handbook of Corrosion Engineering, Mc-Graw-Hill, New York, 1999. 